\title{
Influence of bedding substrates on lying and rising behaviour in dairy heifers
}

\author{
$\mathrm{J} \mathrm{McBride}^{1}$, N E O'Connell ${ }^{2}$ \\ ${ }^{1}$ Agri-Food and Biosciences Institiute, Hillsborough, United Kingdom, ${ }^{2}$ Queens University, Belfast, United Kingdom \\ Email:judith.mcbride@afbini.gov.uk
}

Introduction Problems with rising and lying behaviour in cattle result in lesions to the hocks, knees and teats (Mortensen, 1978). Lying behaviour has been used to assess comfort levels of adult cattle (Hultgren, 2001) and has been shown to differ between different bedding substrates (O' Connell et al., 1997). The aim of the present study was to assess the effect of different bedding substrates on lying and rising behaviour of young dairy heifers. This was to determine if there were any differences in apparent comfort, or in potential injurious behaviour, between the different substrates.

Materials and methods Twenty-eight Holstein Friesian dairy heifers aged between 10 and 12 months were housed in four groups of 7 animals. The current study was part of a larger trial where each group of heifers was subjected to a preference test to determine their relative preference for different bedding substrates in the cubicles. The substrates that were tested included sawdust, shredded paper, chopped straw and a felt covering (mat). Sawdust and straw were provided to a depth of at least $3 \mathrm{~cm}$ and paper to a depth of at least $6 \mathrm{~cm}$. Substrates were replenished as necessary and were placed on top of a felt covering. Each group had access to 14 cubicles and pairs of substrates were compared over a 3 week period in a random order in each group until all combinations had been tested. Prior to the start of each preference test, heifers had a 'forced choice' with each of the two substrates over a 2 day period whereby they only had access to the 7 cubicles containing this substrate. Animals were offered silage ad libitum supplemented with concentrates each day during the experimental period. The data for this study was collected from the second forced choice for each substrate for each group. Animals were video recorded (in 72 hour timelapse) during day 1 of the forced contact period and behavioural recordings were made during the following time periods: 07.00-09.00, 12.45-14.45 and 18.00-20.00 hours. In each observation the number of times a heifer rose from a lying position or lay down was recorded, and the time taken to complete these behaviours was also recorded. A binary score was assigned to each rising behaviour $(0=$ Free, fluid movement or short pause on knees, or $1=$ Long pause on knees, awkward movement of head and neck or abnormal rising sequence). A short pause was determined when the phase where the chest lifted from floor using front knees was less than or equal to 5 seconds. A long pause was when this phase was greater than or equal to 6 seconds (Chaplin, 2000). The proportion of rising incidences that were assigned a binary score of 1 was calculated and used in analysis. Treatment effects were assessed by Analysis of Variance using Genstat Version 12.

Results Treatment effects on different lying and rising parameters are presented in Table 1. Treatment had no significant effect on the average number of lying or rising incidences per observation, or on the time taken to lie down or rise from a lying position. Finally, there were no significant treatment effects on the proportion of rising incidences that were given a score of $1(\mathrm{P}>0.05)$.

Table 1 Effect of bedding substrate in cubicles on lying and rising parameters

\begin{tabular}{|c|c|c|c|c|c|c|}
\hline & \multicolumn{4}{|c|}{ Treatment } & \multirow[t]{2}{*}{ SEM } & \multirow[t]{2}{*}{$\mathrm{P}$} \\
\hline & Straw & Felt mat & Sawdust & Paper & & \\
\hline No. lying incidences (per observation period) & 9.04 & 6.00 & 7.58 & 5.54 & 1.207 & NS \\
\hline No. rising incidences (per observation period) & 10.96 & 7.08 & 10.00 & 8.25 & 1.200 & NS \\
\hline Average duration lying (sec) & 12.74 & 11.80 & 13.47 & 12.63 & 1.055 & NS \\
\hline Average duration rising (sec) & 6.22 & 6.22 & 6.34 & 7.04 & 0.342 & NS \\
\hline Proportion of heifers with " 1 " rising score & 0.086 & 0.129 & 0.089 & 0.079 & 0.0271 & NS \\
\hline
\end{tabular}

Conclusions The fact that there were no significant treatment effects on parameters measured suggests two things. Either (1) the behavioural parameters chosen are not a good indictor of comfort in dairy heifers, or (2) these bedding substrates were equally comfortable for heifers. It is possible that differences in apparent comfort of bedding substrates become more obvious as animals get older and heavier.

Acknowledgements The authors gratefully acknowledge funding from DARDNI.

\section{References}

Chaplin, S.J. 2000. Resting behaviour of dairy cows: Applications to farm assurance and welfare. PhD thesis. University of Glasgow.

Hultgren, J. 2001. Effects of two stall flooring systems on the behaviour of tied dairy cows. Applied Animal Behaviour Science 73, 167-177.

Mortensen, B. 1978. Stanchion barn systems for dairy cows: an ethological evaluation. In: Proceedings of the First World Congress on Ethology Applied to Zootechnics, Madrid, Spain, 181-194.

O’Connell, J.M., Meaney, W.J. 1997. Comparison of shredded newspaper and sawdust as bedding for dairy cows: Behavioural, clinical and economic parameters. Irish Veterinary Journal 50, 167-170. 